\title{
ARTICLE \\ Restoration of uterine redox-balance by methanolic extract of Camellia sinensis in arsenicated rats
}

\author{
Arindam Dey, Sandip Chattopadhyay*, Suryashis Jana, Mukul Kumar Giri, Shamima \\ Khatun, Moumita Dash, Hasina Perveen, Moulima Maity
}

Department of Biomedical Laboratory Science and Management and Clinical Nutrition and Dietetics Division, (UGC Innovative Department), Vidyasagar University, Midnapore, West Bengal 721102, India

\begin{abstract}
Arsenic, an environmental and industrial pollutant causes female reproductive disturbances and female infertility. Several researchers found that the use of Camellia sinensis (CS) (green tea) is effective as an alternative therapeutic strategy in the management of several health ailments. This study explores the role of CS extract against arsenic-induced rat uterine tissue damage. Methanolic extract of CS $(10 \mathrm{mg} / \mathrm{kg}$ BW) was tested concomitantly in arsenic-treated $(10 \mathrm{mg} / \mathrm{kg}$ BW) rats for a duration of two-oestrous cycle length (8 days). CS effectively attenuated arsenic-induced antioxidantdepletion and necrosis in uterine tissue. Rats treated with sodium arsenite showed significantly reduced activities of enzymatic antioxidants like superoxide dismutase (SOD), catalase (CAT) and glutathione peroxidase (GPX) in uterine tissue as evidenced by the results of spectrophotometric and electrozymographic analysis. Co-administration of CS significantly reversed the above oxidative stress markers in uterine tissue along with the histopathological changes in ovarian and uterine tissue. Moreover, an increase in the level of transcription factor NF-KB in the uterine tissue in association with reduced serum levels of vitamin $B_{12}$ and folic acid were mitigated in arsenic fed rats following CS co-administration.

Acta Biol Szeged 62(1):7-15 (2018)
\end{abstract}

\section{Introduction}

Arsenic a heavy metal and toxic element widely distributed in the environment. Arsenic in drinking water is being a major health problem all over the world (Drličková et al. 2013). Long term exposure to arsenic causes lung, skin, liver and kidney cancer (IARC Working Group et al. 2004). Arsenic intoxication during pregnancy may cause stillbirth. Damage of DNA and chromosomal aberration has been also reported during arsenic toxicity (Mazumder and Dasgupta 2011). Previous studies revealed that long term arsenic exposure in animal exhibited reproductive hazards, including the changes of ovarian and testicular steroidogenesis, arrestation of spermatogenesis and folliculogenesis (Sarkar et al. 2003; Chattopadhyay and Ghosh 2010). Reactive oxygen species (ROS) may lead to DNA strand breaks, deletion mutation, micronuclei formation and chromatid exchange (Bau et al. 2002; Kitchin and Wallace 2008). Chronic exposure in humans elevates the necrotic indicator lactate dehydrogenase (LDH) (Calderon et al. 2001). Management of arsenicmediated chronic health hazards primarily depends on the chelation therapy where British Anti Lewisite (BAL) and Dimercaptosulfonic acid (DMSA) are extensively used. But the long-term treatment strategy with these chelating agents is questionable because of its painful intramuscular mode of treatment. These agents also generate several moderate to severe side effects (Flora et al. 2007) among the patients. Hence, the mitigation of arsenic toxicity with the use of a safe, non-invasive strategy is becoming a new challenge. Several investigators used different antioxidants and plant products to counteract arsenic toxicity. Vitamin $\mathrm{C}$, vitamin $\mathrm{E}$, selenium and reduced glutathione $(\mathrm{GSH})$ play pivotal role in maintaining normal ovarian and uterine activities in arsenic-treated rats (Chattopadhyay et al. 2001). Seed extract of Moringa oleifera (Sajina seed) has been proven to actively strengthen the hepatoprotective and antioxidative efficiencies in rats exposed to arsenic (Chattopadhyay et al. 2011). Camellia sinensis (CS), belonging to Theaceae family, contains polyphenolic compound such as epicatechin (EC), epicatechin-3-gallate (ECG), epigallocatechin (EGC) and epigallocatechin-3-gallate (EGCG) and these polyphenols have anti-carcinogenic and anti-mutagenic activities (Yang et al. 1998). The most abundant CS polyphenol, EGCG has antioxidant capac- 
ity, which attenuates arsenic-induced cardiotoxicity in rats (Sun et al. 2016). EGCG also protects doxorubicin induced cardiotoxicity by suppressing oxidative stress, inflammation and apoptosis signals (Saeed et al. 2015).

Aqueous extract of CS leaves showed protective effects against arsenic-induced toxicity and lipid peroxide production in experimental rats (Messarah et al. 2013). Green tea strongly prevents arsenic-induced apoptosis, degeneration and mutagenic DNA damage in liver cells of experimental animal (Acharyya et al. 2014). Considering the above benefits, here we planned to investigate the defensive role of methanolic extract of $C$. sinensis on arsenic-induced uterine disorder in experimental animal model.

\section{Materials and Methods}

\section{Chemicals}

Green tea was collected from local market. The standard rat pellet was obtained from the SAHA Enterprise (Kolkata, India). Vitamin $B_{12}$, folic acid, NF- $x$ B and metallothionine ELISA kit were purchased from the Wuhan fine test, China. Sodium arsenite, chloroform, cyclohexane, hydrogen peroxide, phenol, ethanol and methanol were obtained from SDFCL India. Nitro-blue tetrazolium, nicotinamide adenine dinucleotide, agarose, Tris-base, sodium acetate, nicotinamide adenine dinucleotide phosphate, potassium phosphate and sodium lactate were supplied by SRL (Mumbai, India). Riboflavin was obtained from Loba Chemical (Mumbai, India). Potassium ferricyanide and ethidium bromide were supplied by Merck (Mumbai, India). Ferric chloride, hematoxyline and eosin were obtained from Qualigens (India). Testosterone was obtained from Himedia (India).

\section{Preparation of green tea methanolic extract}

Collected green tea leaves were allowed to dry in an incubator for two days at $40{ }^{\circ} \mathrm{C}$. Dry leaves were crushed and powdered in an electric grinder. This tea powder $(500 \mathrm{~g})$ was dissolved in $1000 \mathrm{ml}$ solvent containing $80 \%$ methanol and 20\% distilled water and followed by mixing in a shaker for two days. After two days the liquid extract was filtered and transferred in a beaker. The liquid deep brown extract was evaporated and preserved in dry powdered form. This dry powder was dissolved in distilled water before treatment in rat.

\section{Animal selection and care}

In this experiment 24 adult female albino rats (6 weeks of age and 90-110 g body weight) were acclimatized for 8 days at $12 \mathrm{~h}$ light-dark cycle with $32 \pm 2{ }^{\circ} \mathrm{C}$ temperature and $50-70 \%$ humidity in the institutional animal house.
Animals were purchased from approved animal provider 'Saha Enterprise' (Kolkata, West Bengal). This study was approved by the Institutional Ethics Committee (IEC/74/C-4/16), and all assay procedures were executed by following the guidelines of the Committee for the Purpose of Control and Supervision of Experiments on Animals (CPCSEA), India. Rats were placed in polycarbonate cages and fed with a standard pellet diet (Saha Enterprise, India) and water ad libitum. Rats were equally distributed in four groups. Control group received distilled water as vehicle. Arsenic treated rats received $10 \mathrm{mg}$ of sodium arsenite / kg body weight by gavage. Another group was administered with only CS extract by gavage at a dose of $100 \mathrm{mg} / \mathrm{kg}$ body weight. Remaining group of rats was co-administered with the same dose of CS extract along with sodium arsenite for 8 days. Prior to the experiment, the estrous cycle of the rats was synchronized by ethynyl oestradiol and the experiment was started at estrous phase. During the entire schedule of treatment body weight of all rats and pattern of estrous cycle were noted. On day nine, rats were sacrificed, and different organs were dissected out for biochemical and histological examinations. All biological samples, including collected serum, were preserved at $-20^{\circ} \mathrm{C}$ in several aliquots for further analysis.

\section{Assessment of malondialdehyde (MDA) and conjugated dienes (CD) levels}

MDA was determined by the reaction against thiobarbituric acid. The amount of MDA formed was measured (Devasagayam et al. 2003) at the absorbance at $530 \mathrm{~nm}$ $\left(\varepsilon=1.56 \times 10^{5} \mathrm{~mol}^{-1} \mathrm{~cm}^{-1}\right)$.

The CD was measured by standard technique where lipids were extracted in presence of chloroform and methanol at the ratio of $2: 1$ and centrifuged at $1000 \mathrm{~g}$ for $5 \mathrm{~min}$. Lipid residues were then dissolved in $1.5 \mathrm{ml}$ of cyclohexane and the absorbance was then measured at $233 \mathrm{~nm}$ to determine the amount of hydroperoxides formed (Kumar 2012).

\section{Assessment of uterine, non-protein, soluble thiol (NPSH)}

Uterine tissue was homogenized in ice cold PBS $(0.1 \mathrm{M}$, $\mathrm{pH}$ 7.4) and centrifuged at $10000 \mathrm{~g}$ for $10 \mathrm{~min}$ at $4{ }^{\circ} \mathrm{C}$. The supernatant was then used for the determination of NPSH by standard DTNB (5, 5"-dithiobis-2-nitrobenzoic acid) method with a slight change. Here, precipitation of protein was obtained by sulfosalicialic acid and supernatant was mixed with $0.1 \mathrm{M}$ sodium phosphate buffer containing DTNB. Finally, the absorbance was taken at $412 \mathrm{~nm}$ (Mieyal et al. 2008). 


\section{Assessment of superoxide dismutase (SOD), catalase (CAT), peroxidase and lactate dehydrogenase (LDH) in native gel}

To determine SOD activity, homogenized uterine tissue in ice cold PBS (1.0 mM pH 7.4) was centrifuged at 10 $000 \mathrm{~g}$ for $20 \mathrm{~min}$ at $4{ }^{\circ} \mathrm{C}$. The $40 \mu \mathrm{g}$ of the tissue protein extract was added to the 12\% PAGE. Achromatic bands were achieved against a dark blue background following light exposure in the presence of nitro-blue tetrazolium and riboflavin (Weydert and Cullen 2010).

Proteins $(60 \mu \mathrm{g})$ were electrophoresed on $8 \%$ PAGE to measure catalase activity in uterine tissue extract. Gels were kept at $0.003 \% \mathrm{H}_{2} \mathrm{O}_{2}$ solution for $10 \mathrm{~min}$ and stained with $2 \%$ potassium ferricyanide and $2 \%$ ferric chloride. Bluish yellow bands were observed against a blue, green background (Lewis et al. 2005).

For the determination of GPx activity, native PAGE (8\%) was used. The level of GPx was determined by the removal of peroxide for the transformation of potassium ferricyanide to ferrocyanide between samples. Elimination of peroxide by GPx inhibited the combination with ferric chloride, which allowed the appearance of the achromatic clear band on the green-blue gel where GPx was present (Liu et al. 2006).

A $8.0 \%$ agarose gel in $50 \mathrm{mM}$ Tris- $\mathrm{HCl}$ buffer $(\mathrm{pH}$ 8.2) was used for the detection of serum LDH enzyme. Serum $(20 \mu \mathrm{l})$ was loaded into the gel to electrophorese at 170 volts. Agarose gel was stained by using a cocktail of 1.0 M Tris, tetrazolium blue, phenazine methosulphate, $\mathrm{Na}$-lactate and NAD. And then incubated at $37^{\circ} \mathrm{C}$ to mature the colour reaction following rinsing the gels under water in the presence of light (Brandt et al. 1987).

\section{DNA fragmentation study}

Uterine tissue was used: it was lysed with $500 \mu l$ of lysis buffer and centrifuged (12 $000 \mathrm{rpm})$ at $4{ }^{\circ} \mathrm{C}$ for $15 \mathrm{~min}$. Supernatant was then mixed with 1:1 mixture of phenol and chloroform with a gentle agitation for 5 minutes, followed by centrifugation and precipitation in two parts of cold ethanol and one-tenth part of sodium acetate. After spinning down and decanting, the precipitate was resuspended in $30 \mu \mathrm{l}$ of deionized water, $5 \mu \mathrm{l}$ of RNAase solution and $5 \mu \mathrm{l}$ of loading buffer followed by an incubation for $30 \mathrm{~min}$ at $37^{\circ} \mathrm{C}$. Then the samples were run in $0.8 \%$ agarose gel with ethidium bromide at $65 \mathrm{~V}$ and visualized in the BioRad gel documentation system (Garcia-Martinez et al. 1993).

\section{Comet assay}

Glass slides were precoated with $1 \%$ agarose. A combination of $7.5 \mathrm{ml}$ of low melting point agarose (0.6\%) in PBS at $37^{\circ} \mathrm{C}$ and $2.5 \mathrm{ml}$ of uterine cell suspension was prepared before placing the cell suspension on the agarose coated glass slide and electrophoresed with alkaline electrophoresis buffer (0.3 M NaOH and $1 \mathrm{mM}$ EDTA) for 30 min at $25 \mathrm{~V}$. Then the slides were stained with ethidium bromide and observed under a fluorescence microscope (Nikon Eclipse LV 100 POL), with the VisComet Impuls Bild Analyse software (Singh et al. 1988).

\section{Assay of ovarian 17beta- hydroxysteroid dehydrogenase (17 $\beta$-HSD) activity}

Assessment of ovarian $17 \beta$-HSD activity was performed by the homogenization of ovarian tissue at $4{ }^{\circ} \mathrm{C}$ in $20 \%$ spectroscopic grade glycerol containing $5 \mathrm{mM}$ potassium phosphate and $1 \mathrm{mM}$ EDTA at a tissue concentration of $10 \mathrm{mg} / \mathrm{ml}$. Residual supernatant was mixed with $25 \mathrm{mg}$ of crystalline BSA, $0.3 \mu \mathrm{M}$ of testosterone and $1.1 \mu \mathrm{M}$ of NADP and the absorbance was read at $340 \mathrm{~nm}$ against blank (Jarabak et al. 1962).

\section{Analysis of vitamin $B_{12}$, folic acid and NF-KB and metallothionein (MT-I)}

The serum levels of vitamin $B_{12}$ (Cat no. ER1579), folic acid (Cat no. EU0381), NF- $x$ B (Cat no. ER1579) and metallothionein (Cat no. ER0447) were measured by ELISA technique according to the procedure recommended by the manufacturer (Wunhan Fine Test, China).

\section{Serum hormone levels and histology of ovary and uterus}

Serum level of oestradiol was measured by ELISA kits (Cat no. ER1507), according to the procedures recommended by the manufacturer (Wunhan Fine test, China).

Uterine and ovarian tissues were embedded in paraffin, sectioned with $5 \mu \mathrm{m}$ thickness, and then stained with haematoxylin (Harris) and eosin and observed under a light microscope (Olympus, CX21i; magnification x 400).

\section{Statistical analysis}

Data were expressed in terms of mean $\pm S E$, where $n=6$ in all groups. Arsenic and CS co-administered groups were compared with the control by utilizing ANOVA followed by post-hoc Dunnett's multiple comparison test. Statistical significance was considered at the level of $\mathrm{p}<0.05$.

\section{Results}

\section{General observations}

No significant difference was found in their body weight between the control, arsenic-treated and CS co-administered group before and after treatment (Table 1). Here, organo-somatic indices are expressed by the weight of the organs in terms of the percentage of body mass. In case of arsenic-treated group, the weight of the reproductive organs was significantly decreased in comparison 
Dey et al.

Table 1. Effect of methanolic extract of CS on final body weights and organo-somatic indices in arsenic ingestion rats. The data represent mean $\pm \mathrm{SE}, \mathrm{N}=6$, ANOVA followed by post-hoc Dunnett's multiple comparison test. Statistical significance was considered at the level of ${ }^{*} p<0.05$.

\begin{tabular}{lllll}
\hline & \multicolumn{2}{c}{ Body weight $(\mathrm{g})$} & & \multicolumn{2}{c}{ Organo-somatic indices $(\mathrm{g} \%)$} \\
\cline { 2 - 3 } & Initial & Final & Ovary in pair & $0.181 \pm 0.020$ \\
Control & $118.71 \pm 8.21$ & $129.6 \pm 7.95$ & $0.0504 \pm 0.003$ & $0.099^{\star} \pm 0.010$ \\
Arsenic & $108.87 \pm 5.53$ & $110.8 \pm 5.35$ & $0.0329^{*} \pm 0.002$ & $0.159 \pm 0.022$ \\
CS & $115.5 \pm 3.85$ & $117 \pm 5.13$ & $0.0498 \pm 0.001$ & $0.166 \pm 0.022$ \\
As $^{\prime \prime \prime}+$ CS & $110.5 \pm 4.83$ & $110 \pm 5.11$ & $0.0491 \pm 0.001$ & 0.13 \\
\hline
\end{tabular}
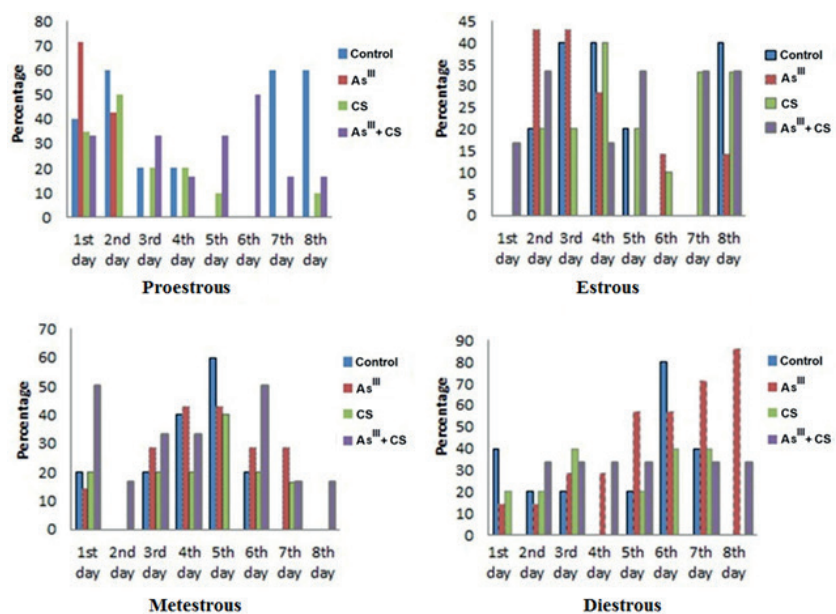

Figure 1. Effect of arsenic and methanolic extract of CS on pattern of estrous cycle of arsenic treated rats.

to control (Table 1). Co-treatment with C. sinensis (CS) attenuated this deleterious effect of arsenic.

\section{Pattern of vaginal smear}

The pattern of estrous cycle was noticed during the entire experimental schedule. Vaginal fluid was collected regularly, and was stained with Leishman stain. Results showed that rats continuously shifted towards consistent metestrous or diestrous phase after the first 4 days of treatment with arsenic (Fig. 1). Maintenance of normal estrous cycle was achieved by application of methanolic extract of CS in arsenic ingested rats (Fig. 1).

\section{Status of oxidative stress markers}

Uterine MDA and CD showed a significant elevation in

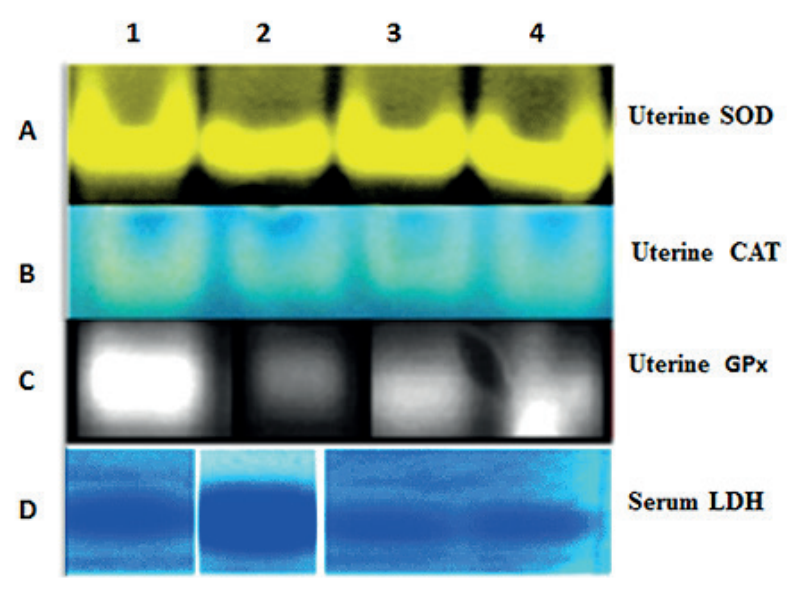

Figure 2. Protective effect of methanolic extract of CS on uterine tissue SOD, CAT, GPx and serum LDH in As'l' intoxicated rats. Panel A, B, C and D: SOD, CAT, GPx and LDH activity on native gel. Lane 1: control; lane 2: arsenic; lane 3: CS; lane 4: arsenic + CS.

rats fed with sodium arsenite (Table 2). Adminsitration of methanolic extract of CS to the arsenic treated rats caused a significant improvement of this lipid peroxidation state in the uterus (Table 2). NPSH was significantly reduced following the ingestion of arsenic whereas CS co-administration in arsenic fed rats caused significant reverseal of this parameter (Table 2).

Electrozymogram of SOD, catalase and GPx in uterine tissue showed comparatively weaker band strength in the arsenic treated group compared to control (Fig. 2). On the other hand, intense band strength was seen in CS and arsenic treated rats. Serum LDH zymogram was obtained to assess the necrotic risk factor. In arsenic-treated group a very strong band of LDH was observed in contrast to

Table 2. The defensive role of methanolic extract of CS on arsenic affected rats on the status of free radical generation and NPSH. Data represent mean $\pm \mathrm{SE}$ where $\mathrm{N}=6$ evaluated by ANOVA followed by post-hoc Dunnett's multiple comparison test. Statistical significance was considered at the level of $* * * p<0.001$, and $* * p<0.01$.

\begin{tabular}{|c|c|c|c|c|}
\hline & Control & $\mathrm{As}^{\prime \prime \prime}$ & $\mathrm{CS}$ & $\mathrm{CS}+\mathrm{As}^{\mathrm{II}}$ \\
\hline MDA (nmol/mg of tissue) & $29.37 \pm 3.09$ & $67.91 \pm 3.87 * * *$ & $28.85 \pm 1.51$ & $23.77 \pm 1.54$ \\
\hline $\mathrm{CD}$ (nmol/mg of tissue) & $14.33 \pm 0.88$ & $27.8 \pm 1.09 * * \star$ & $15.54 \pm 0.66^{*}$ & $18.43 \pm 0.59 * *$ \\
\hline NPSH ( $\mu \mathrm{g} / \mathrm{g}$ of protein) & $15.46 \pm 0.33$ & $6.12 \pm 0.31 * * *$ & $14.58 \pm 0.35$ & $14 \pm 0.66$ \\
\hline
\end{tabular}


Table 3. Defensive effect of methanolic extract of CS against arsenic-induced ovarian steroidogenesis. The data represent mean $\pm S E, N=6, A N O V A$ followed by post-hoc Dunnett's multiple comparison test. Statistical significance was considered at the level of ***p<0.001, and **p<0.01.

\begin{tabular}{|c|c|c|c|c|}
\hline & Control & $A s^{\prime \prime \prime}$ & $\mathrm{CS}$ & $\mathrm{CS}+\mathrm{As} \mathrm{s}^{\prime \prime \prime}$ \\
\hline 17â HSD (unit/mg of tissue) & $0.0344 \pm 0.004$ & $0.0052 \pm 0.002 * \star *$ & $0.032 \pm 0.001$ & $0.022 \pm 0.003^{*}$ \\
\hline Oestradiol (ng/ml) & $27 \pm 0.45$ & $4.0 \pm 0.40 * \star *$ & $23 \pm 0.81$ ** & $16 \pm 0.90 * \star *$ \\
\hline
\end{tabular}
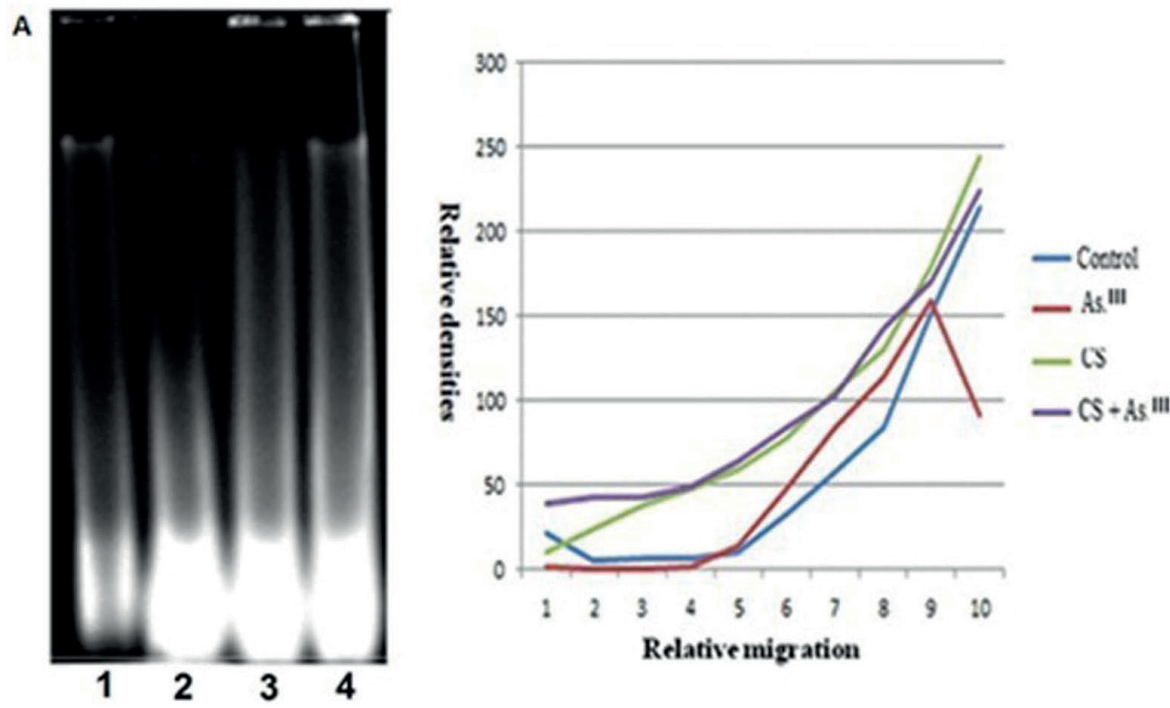
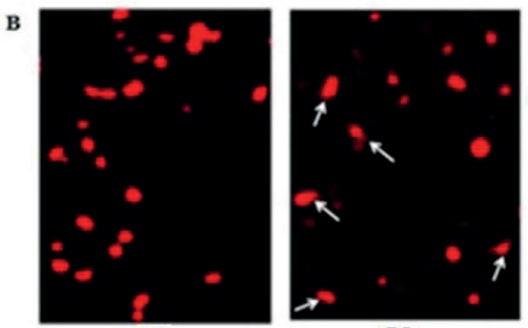

B1

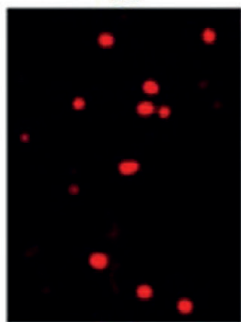

B3

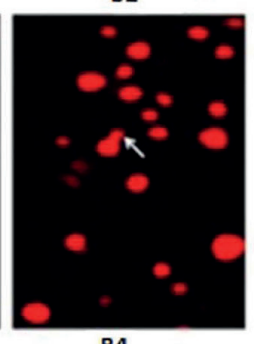

B4

Figure 3. Effect of methanolic extract of CS on the DNA fragmentation (Panel A) with graphical representation and the comet assay (Panel B) in uterine cells of female rats treated with arsenic. Lanes in panel A: 1: control; 2: arsenic; 3: CS; 4: arsenic + CS. Panels in B: B1: control; B2: arsenic; B3: CS; B4: arsenic + CS. Arrows indicate comet formation.

control group (Fig. 2). This nature of the band was substituted by a weaker expression pattern when arsenic-treated rats were co-ingested with CS extract (Fig. 2).

\section{Status of uterine DNA}

Arsenic exposure lead to DNA damage, but supplementation of CS extract had a beneficial effect against this damage (Fig. 3A). The DNA degradation was more prominent in arsenic-treated rats compared to control rats (Fig 3A). Migration of the exposed DNA occurred with the less intense band in arsenic-treated rats in comparison to control DNA as evidenced from densitometric analysis (Fig. 3A). However, this damage recovered successfully in the CS supplemented group (Fig. 3A). Comet assay showed that arsenic-treated uterine DNA cells were de- graded and broken (Fig. 3B). This was finally restrained by the supplementation of CS extract as demonstrated from the comparatively less number of comets in this group (Fig. 3B).

\section{Ovarian steroidogenesis and histopathology of ovary and uterus}

A notable inhibition in the activity of ovarian $17 \beta$ HSD was observed in arsenic exposed rats compared with control, while co-administration of CS extract significantly protected the activity of this steroidogenic enzyme (Table 3 ).

A diminished oestradiol level was observed following 8 days of arsenic treatment in comparison with control (Table 3). On the contrary, CS co-treatment in arsenic fed rats increased this hormonal signalling (Table 3).

Table 4. Effect of methanolic extract of CS on vitamins, NF-KB, and metallothionein level of arsenic-treated rats. The data represent mean \pm SE, N=6, ANOVA followed by post-hoc Dunnett's multiple comparison test. Statistical significance was considered at the level of, $* \star \star p<0.001$, and $* \star p<0.01$.

\begin{tabular}{|c|c|c|c|c|}
\hline & Control & $A s^{\prime \prime \prime}$ & $\mathrm{CS}$ & $C S+A s^{\prime \prime I}$ \\
\hline Vitamin $B_{12}(\mathrm{ng} / \mathrm{ml})$ & $23.32 \pm 1.05$ & $10.71 \pm 0.39 * *$ & $22.47 \pm 0.80$ & $18.23 \pm 0.42^{\star}$ \\
\hline Folic acid (ng/ml) & $1231.5 \pm 43.71$ & $918 \pm 16.01 * \star *$ & $1125.1 \pm 34.70$ & $1047 \pm 29.50 * *$ \\
\hline NF-kB (ng/ml) & $6.11 \pm 0.285$ & $9.42 \pm 0.311 * \star \star$ & $5.77 \pm 0.223$ & $6.72 \pm 0.166$ \\
\hline Metallothionine (MT-I) (ng/ml) & $12.5 \pm 0.28$ & $31 \pm 0.92 * * \star$ & $14 \pm 1.03 *$ & 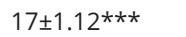 \\
\hline
\end{tabular}


Normal uterine histology is composed of three layers, the inner one is endometrium, middle layer is myometrium and the outer layer is serosa (Fig. 4). Following the exposure of arsenic there was a thinning of the uterine layer along with a remarkable loss of uterine secretory glands in the arsenic ingested group (Fig. 4). CS supplementation reverts back the above degeneration of the uterine layers towards normalcy (Fig. 4).
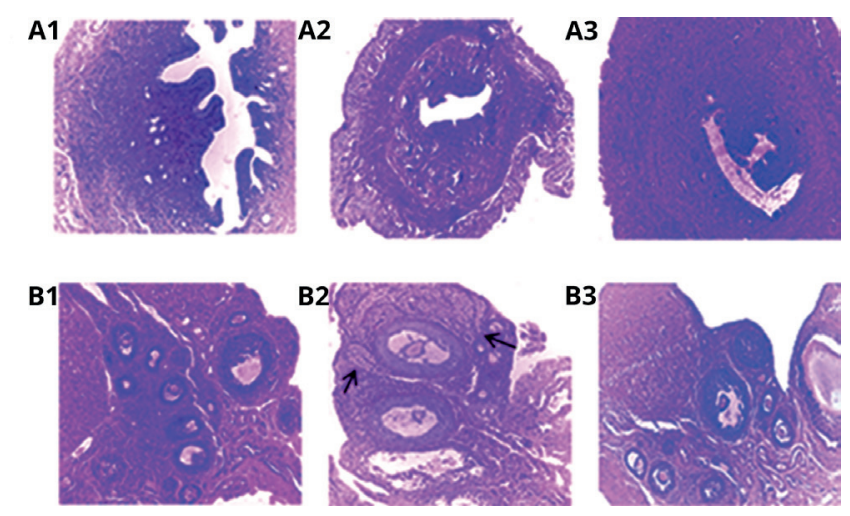

Figure 4. Effect of methanolic extract of CS on uterine (A) and ovarian (B) histo-architecture. Panels $A 1$ and B1: vehicle treated control; $A 2$ and B2: arsenic; A3 and B3: arsenic + methanolic extract of CS. Arrow indicates follicular atresia.

Significant shrinkage or decrease in the number of graafian follicles, with a higher degree of follicular regression and follicular atresia, was seen in the arsenic treated rats compared to the controls (Fig. 4). Supplementation with CS extract resulted in significant reappearance of a growing number of developing follicles followed by lesser number of immature follicles (Fig. 4).

\section{Status of vitamin $B_{12}$, folic acid, NF-KB and metallothio- nein (MT-I)}

There was a decreased level of vitamin $\mathrm{B}_{12}$ and folic acid in arsenic-treated group when compared to the control rats (Table 4). Methanolic extract of CS significantly reversed this effect. A notable elevation of uterine NF$x \mathrm{~B}$ was also noted in arsenic-treated group (Table 4) while co-administration of the CS methanolic extract significantly reduced the level of this transcription factor towards normalcy. We also assessed metallothionein in the liver to bio-monitor the deposition of this metalloid in tissue. The result showed an increase level of MT-1 in $\mathrm{As}^{\mathrm{III}}$ treated group compared to control group (Table 4). Supplementation with CS methanolic extract significantly decreased this elevation of hepatic MT-1 level.

\section{Discussion}

Our results showed a low-level expression of SOD, catalase and GPx as faint bands in Figure 2 in arsenic fed rats compared to the control. SOD, catalase and GPx are considered as the first line of defense against oxidative injury at the cellular level. The NPSH, precursor of GSH, was significantly deprived by arsenic and was returned towards control level when the arsenicated rats received methanolic extract of CS (Table 2). Hence, increased level of free radical generation and diminished enzymatic antioxidant activity in arsenic exposed rats may lead to DNA damage due to the formation of $\mathrm{H}_{2} \mathrm{O}_{2}$ and arsenic peroxyl radicals (Maiti et al. 2012). Elevated uterine MDA and CD levels (Table 2) indicated an increase in lipid peroxidation. Endometrium is the potential site in the female reproductive organ for the generation of superoxide anions (Akram et al. 2010), and arsenic has been shown to induce endometrial carcinogenicity or cellular toxicity that may lead to cell death (Du et al. 2012).

In our experiment arsenic-treated rats lost their normal estrous cyclicity (Fig. 1) and moved towards consistent diestrous phase along with the reduced weight of ovary and uterus (Table 1). Reduced activity of steroidogenic enzyme $17 \beta-H S D$ may result in suppression of oestradiol $\left(E_{2}\right)$ signalling (Table 3). Suppression of $E_{2}$ (Table 3) and deterioration of follicular maturation (Fig. 4) in response to $\mathrm{As}{ }^{\mathrm{III}}$ lead to cellular degeneration in uterine layers (Fig. 4). Several studies demonstrated that during ovarian aging high level of ROS is responsible for DNA damage (Gore-Langton and Daniel 1990). Reactive oxygen species play a critical role in the alteration of physiological and reproductive functions like oocyte maturation and luteolysis. Arsenic probably binds to estrogen receptor (ER) and inhibits $E_{2}$ binding to the estrogen receptor alpha (ER $\alpha)$ (Bae-Jump et al. 2008). Exposure to arsenic caused a degradation of circulating levels of vitamin $B_{12}$ and folate, (Table 4). These two vitamins are indispensable to protect the reproductive organs from necrosis and have a protective role by diminishing serum LDH level (Fig 2D) as a consequence of an inverse relationship between the serum $\mathrm{LDH}$ activities and serum vitamin $\mathrm{B}_{12}$-folate levels (Maity et al. 2017). LDH expression was noticeably elevated (Fig. 2D) in arsenic fed rats since As ${ }^{\mathrm{III}}$ is directly linked to the development of necrosis (Karim et al. 2010).

The liver is the most sensitive to arsenic and is the site of the synthesis of low molecular weight, cysteine rich metal binding antioxidant, MT, in response. MT-1 is required to ensure protection against arsenic toxicity and has an important role in heavy metal detoxification as well as essential metal homeostasis (Cai et al. 2006). The maintenance of cellular MT-I level is regulated by IKK-NF- $x$ B pathway which suspends the generation of 
ROS. ROS driven apoptosis is attributed to the failure of IKK-NF- $x B$ (Peng et al. 2007). A high uterine NF- $x$ B in arsenic exposed group (Table 4) was in accordance with reports on arsenic damaging the tissue via activation of NF- $x$ B signalling pathway (Felix et al. 2005). The level of MT-I was normalized in presence of CS co-administration (Table 4). There is apparently an inverse correlation between MT and ER (Ioachim et al. 2000), as MT gene is potentially down-regulated by ER $\alpha$ (Surowiak et al. 2005), and arsenic trioxide has been supposed to exert anti-estrogenic activity by down regulating the expression of $\mathrm{ER} \alpha$ (Bae-Jump et al. 2008).

Co-administration of methanolic CS extraction can reverse uterine ROS production with a concomitant repairing of the anti-oxidant enzyme activities (Fig. 2) in arsenic treated rats. The methanolic CS extract significantly reduced uterine DNA degradation in arsenic fed rats (Fig. 3A-B). The mechanism of counteracting arsenic-mediated uterine damage might be linked to the antioxidant, scavenging and chelating properties of C. sinensis (CS) (Cao et al. 2015). It was established that methanolic and water extracts of $C$. sinensis contain an enormous amount of catechins and flavonoids (Noor 2016). Catechins, present in green tea, have a strong scavenging capacity against superoxide, hydrogen peroxide, hydroxyl radicals. They have the ability to chelate with metals because of the presence of catechol structural motif (El-Shahat et al. 2009). EGCG-3 and EGC are the most abundant and important polyphenols scavenging a wide range of free radicals including the active hydroxyl; and the chemical structure of catechins play a crucial role in their antioxidant effect (Skrzydlewska et al. 2005). The anti-oxidative, anti-apoptotic, and metal chelating properties of EGC are helpful to suppress the generation of arsenic-induced oxidative stress (Rice-Evans et al. 1996; Guo et al. 1996). However, our experiment showed that green tea protects uterine tissue from a state of redox imbalance by up regulating enzymatic antioxidants (Fig. 2).

Co-administration with CS could significantly normalize the activity of LDH (Fig. 2). CS supplementation may effectively rescue the uterus from apoptotic degeneration and this was indicated from the weakened band intensity of serum LDH compared to arsenic-treated rats (Fig. 2). The presence of the pyrogallol motif in EGCG conveys its strong metal chelating ability. Supplementation with CS extract resulted in comparatively lower level of NF- $x \mathrm{~B}$, similar to control. EGCG 3 can block NF- $x \mathrm{~B}$ activation by downregulation of NF- $\times \mathrm{B}$ kinase in the intestinal epithelial cell line IEC-6 (Yang et al. 2001). In this study arsenic-mediated apoptotic and necrotic processes were detected by single cell DNA assay and DNA fragmentation picture (Fig. 3, lane 2). CS co-treatment significantly reduced DNA degradation and this may highlight the efficacy of CS polyphenols to protect the cells from arsenic-mediated mutagenic DNA breakage and tissue necrosis (Ndiaye et al. 2005). Supplementation with CS was able to maintain the circulating level of vitamin $B_{12}$ and folic acid in arsenicated rats (Table 4). Previous studies showed that vitamin $B_{12}$ is present in green tea (Kittaka-Katsura et al. 2004) Vitamin $B_{12}$ and folate maintain the level of endogenous methionine where folic acid acts as methyl group donor and vitamin $\mathrm{B}_{12}$ act as co-factor for the synthesis of methionine (Sahin et al. 2003). Therefore, CS mediated maintenance of these vitamins contributes to the attenuation of arsenic toxicity, and so, to the prevention of reproductive organ necrosis. It is confirmed from the above information that CS has a protective effect against oxidative stress induced ovarian and uterine damage by the rebuilding the normal uterine and ovarian histological structure. Co-administration with CS significantly increased plasma oestradiol level and ovarian $17 \beta-H S D$ activity and that was helpful for the restoration of normal histoarchitecture of ovary and uterus (Fig. 4).

From the above study, we may conclude that green tea methanolic extract has a potential role to improve uterine anti-oxidant defense system and restore normal ovarian-uterine histoarchitecture either by its chelating action with arsenic or by sustaining B vitamins.

\section{Acknowledgement}

The authors acknowledged the funding from the Department of Science and Technology, Government of West Bengal for this investigation (1212(Sanc.)/ST/P/ S\&T/1G-13/2015).

\section{References}

Acharyya N, Chattopadhyay S, Maiti S (2014) Chemoprevention against arsenic-induced mutagenic DNA breakage and apoptotic liver damage in rat via antioxidant and SOD1 upregulation by green tea (Camellia sinensis) which recovers broken DNA resulted from arsenic- $\mathrm{H} 2 \mathrm{O} 2$ related in vitro oxidant stress. J Environ Sci Health (Part C) 32:338-361.

Akram Z, Jalali S, Shami SA, Ahmad L, Batool S, Kalsoom O (2010) Adverse effects of arsenic exposure on uterine function and structure in female rat. Exper Toxicol Pathol 62:451-459.

Bae-Jump VL, Zhou C, Boggess JF, Gehrig PA (2008) Arsenic trioxide $\left(\mathrm{As}_{2} \mathrm{O}_{3}\right)$ inhibits expression of estrogen receptor-alpha through regulation of the mitogen-activated protein kinase (MAPK) pathway in endometrial cancer 
cells. Reprod Sci 15:1011-1017.

Bau DT, Wang TS, Chung CH, Wang AS, Wang AS, Jan KY (2002) Oxidative DNA adducts and DNA-protein crosslinks are the major DNA lesions induced by arsenite. Environ Health Perspect 110(S3):753-756.

Brandt RB, Laux JE, Spainhour SE, Kline ES (1987) Lactate dehydrogenase in rat mitochondria. Arch Biochem Biophys 259:412-422.

Calderon J, Navarro ME, Jimenez-Capdeville ME, SantosDiaz MA, Golden A, Rodriguez-Leyva I, Díaz-Barriga F (2001) Exposure to arsenic and lead and neuropsychological development in Mexican children. Environ Res 85:69-76.

Cao SQ, Hu YH, Zhang L, Liu, SN, Wang F, Shu-Hua XI. (2015) Effects of dimethylarsinic acid on expression levels of IKK $\alpha$ and $\mathrm{p} 65$ in bladder epithelial cells of rats. Chin J Ind Med 2:95-97.

Chattopadhyay S, Ghosh D (2010) The involvement of hypophyseal-gonadal and hypophyseal-adrenal axes in arsenic-mediated ovarian and uterine toxicity: modulation by hCG. J Biochem Mol Toxicol 24:29-41.

Chattopadhyay S, Ghosh S, Debnath J, Ghosh D (2001) Protection of sodium arsenite-induced ovarian toxicity by coadministration of L-ascorbate (vitamin C) in mature Wistar strain rat. Arch Environ Contam Toxicol 41:83-89.

Chattopadhyay S, Maiti S, Maji G, Deb B, Pan B, Ghosh D (2011) Protective role of Moringa oleifera (Sajina) seed on arsenic-induced hepatocellular degeneration in female albino rats. Biol Trace Elem Res 142:200-212.

Devasagayam TPA, Boloor KK, Ramasarma T (2003) Methods for estimating lipid peroxidation: an analysis of merits and demerits. Ind J Biochem Biophys 40:300-308.

Drličková G, Vaculík M, Matejkovič P, Lux A (2013) Bioavailability and toxicity of arsenic in maize (Zea mays L.) grown in contaminated soils. Bull Environ Contam Toxicol 91:235-239.

Du J, Zhou N, Liu H, Jiang F, Wang Y, Hu C, Li Z (2012) Arsenic induces functional re-expression of estrogen receptor $\alpha$ by demethylation of DNA in estrogen receptornegative human breast cancer. PLOS ONE 7:1-10.

El-Shahat AER, Gabr A, Meki AR, Mehana ES (2009) Altered testicular morphology and oxidative stress induced by cadmium in experimental rats and protective effect of simultaneous green tea extract. Int J Morphol 27:757-764.

Felix K, Manna SK, Wise K, Barr J, Ramesh GT (2005) Low levels of arsenite activates nuclear factor- $x \mathrm{~B}$ and activator protein-1 in immortalized mesencephalic cells. J Biochem Mol Toxicol 19:67-77.

Flora SJS, Bhadauria S, Kannan GM, Singh N (2007) Arsenicinduced oxidative stress and the role of antioxidant supplementation during chelation: a review. J Environ Biol 28:333-347.

Garcia-Martinez V, Macias D, Ganan Y, Garcia-Lobo JM,
Francia MV, Fernandez-Teran MA, Hurle JM (1993). Internucleosomal DNA fragmentation and programmed cell death (apoptosis) in the interdigital tissue of the embryonic chick leg bud. J Cell Sci 106:201-208.

Gore-Langton RE, Daniel SA (1990) Follicle-stimulating hormone and oestradiol regulate antrum-like reorganization of granulosa cells in rat preantral follicle cultures. Biol Reprod 43:65-72.

Guo Q, Zhao B, Li M, Shen S, Xin W (1996) Studies on protective mechanisms of four components of green tea polyphenols against lipid peroxidation in synaptosomes. BBA- Lipid Lipid Met 1304:210-222.

IARC Working Group on the Evaluation of Carcinogenic Risks to Humans, World Health Organization, \& International Agency for Research on Cancer (2004) Some drinking-water disinfectants and contaminants, including arsenic. 84:14-20.

Ioachim EE, Kitsiou E, Carassavoglou C, Stefanaki S, Agnantis NJ (2000) Immunohistochemical localization of metallothionein in endometrial lesions. J Pathol 191:269273.

Jarabak J, Adams JA, Williams-Ashman HG, Talalay P (1962) Purification of a $17 \beta$-hydroxysteroid dehydrogenase of human placenta and studies on its transhydrogenase function. J Biol Chem 237:345-357.

Karim MR, Salam KA, Hossain E, Islam K, Ali N, Haque A, Himeno S (2010) Interaction between chronic arsenic exposure via drinking water and plasma lactate dehydrogenase activity. Sci Total Environ 409:278-283.

Kitchin KT, Wallace K (2008) Evidence against the nuclear in situ binding of arsenicals-oxidative stress theory of arsenic carcinogenesis. Toxicol Appl Pharmacol 232:252-257.

Kittaka-Katsura H, Watanabe F, Nakano Y (2004) Occurrence of vitamin $B_{12}$ in green, blue, red, and black tea leaves. J Nutr Sci Vitaminol 50:438-440.

Kumar A (2012) Effect of simvastatin on paraxonase 1 (PON1) activity and oxidative stress. In Kumar A (ed.), Significance of Lipid Profile Assay as Diagnostic and Prognostic Tool. Create Space Independent Publishing Platform, California, 105-109.

Lewis A, Du J, Liu J, Ritchie JM, Oberley LW, Cullen JJ (2005) Metastatic progression of pancreatic cancer: changes in antioxidant enzymes and cell growth. Clin Exp Metastasis 22:523-532.

Liu J, Du J, Zhang Y, Sun W, Smith BJ, Oberley LW, Cullen JJ (2006) Suppression of the malignant phenotype in pancreatic cancer by overexpression of phospholipid hydroperoxide glutathione peroxidase. Hum Gene Ther 17:105-116.

Ma J, Stampfer MJ, Christensen B, Giovannucci E, Hunter DJ, Chen J, Rozen R (1999) A polymorphism of the methionine synthase gene: association with plasma folate, vitamin $\mathrm{B}_{12}$, homocyst(e)ine, and colorectal cancer risk. 
Cancer Epidemiol Biomark Prev 8:825-829.

Maiti S, Chattopadhyay S, Deb B, Samanta T, Maji G, Pan B, Ghosh D (2012) Antioxidant and metabolic impairment result in DNA damage in arsenic-exposed individuals with severe dermatological manifestations in Eastern India. Environ Toxicol 27:342-350.

Maity M, Perveen H, Dash M, Jana S, Khatun S, Dey A, Mandal AK, Chattopadhyay S (2017) Arjunolic acid improves the serum level of vitamin $B_{12}$ and folate in the process of the attenuation of arsenic-induced uterine oxidative stress. Biol Tres Elem Res 182:78-90.

Mazumder DG, Dasgupta UB (2011) Chronic arsenic toxicity: studies in West Bengal, India. Kaohsiung J Med Sci 27:360-370.

Messarah M, Saoudi M, Boumendjel A, Kadeche L, Boulakoud MS, Feki AE (2013) Green tea extract alleviates arsenic-induced biochemical toxicity and lipid peroxidation in rats. Toxicol Ind Health 29:349-359.

Mieyal JJ, Gallogly MM, Qanungo S, Sabens EA, Shelton MD (2008) Molecular mechanisms and clinical implications of reversible protein S-glutathionylation. Antioxid Redox Signal 10:1941-1988.

Ndiaye M, Chataigneau M, Lobysheva I, Chataigneau T, Schini-Kerth VB (2005) Red wine polyphenol-induced, endothelium-dependent NO-mediated relaxation is due to the redox-sensitive PI3-kinase/Akt-dependent phosphorylation of endothelial NO-synthase in the isolated porcine coronary artery. FASEB J 19:455-457.

Noor S. Latteef (2016) Phytochemical, antibacterial and antioxidant activity of Camellia sinensis methanolic and aqueous extracts. IOSR J Pharm Biol Sci 11:113-119.

Peng Z, Peng L, Fan Y, Zandi E, Shertzer HG, Xia Y (2007) A critical role for IxB kinase $\beta$ in metallothionein-1 expression and protection against arsenic toxicity.J Biol Chem 282:21487-21496.

Refsum H (2001) Folate, vitamin $B_{12}$ and homocysteine in relation to birth defects and pregnancy outcome. $\mathrm{Br} \mathrm{J}$ Nutr 85:S109-S113.

Rice-Evans CA, Miller NJ, Paganga G (1996) Structureantioxidant activity relationships of flavonoids and phenolic acids. Free Radic Biol Med 20:933-956.

Saeed NM, El-Naga RN, El-Bakly WM, Abdel-Rahman HM,
ElDin RAS, El-Demerdash E (2015) Epigallocatechin3 -gallate pretreatment attenuates doxorubicin-induced cardiotoxicity in rats: a mechanistic study. Biochem Pharmacol 95:145-155.

Sahin K, Onderci M, Sahin N, Gursu MF, Kucuk O (2003) Dietary vitamin $\mathrm{C}$ and folic acid supplementation ameliorates the detrimental effects of heat stress in Japanese quail. J Nutr 133:1882-1886.

Sarkar M, Chaudhuri GR, Chattopadhyay A, Biswas NM (2003) Effect of sodium arsenite on spermatogenesis, plasma gonadotrophins and testosterone in rats. Asian J Androl 5:27-32.

Singh NP, McCoy MT, Tice RR, Schneider EL (1988) A simple technique for quantitation of low levels of DNA damage in individual cells. Exp Cell Res 175:184-191.

Skrzydlewska E, Augustyniak A, Michalak K, Farbiszewski $\mathrm{R}$ (2005) Green tea supplementation in rats of different ages mitigates ethanol-induced changes in brain antioxidant abilities. Alcohol 37:89-98.

Smid-Koopman E, Kuhne LC, Hanekamp EE, Gielen SC, De Ruiter PE, Grootegoed JA, Blok LJ (2005) Progesteroneinduced inhibition of growth and differential regulation of gene expression in PRA-and/or PRB-expressing endometrial cancer cell lines. J Soc Gynecol Investig 12:285-292.

Sun TL, Liu Z, Qi ZJ, Huang YP, Gao XQ, Zhang YY (2016) (-)-Epigallocatechin-3-gallate (EGCG) attenuates arsenic-induced cardiotoxicity in rats. Food Chem Toxicol 93:102-110.

Surowiak P, Matkowski R, Materna V, Gyorffy B, Wojnar A, Pudelko M, Zabel M (2005) Elevated metallothionein (MT) expression in invasive ductal breast cancers predicts tamoxifen resistance. Histol Histopathol 20:1037-1044.

Yang CS, Chen L, Lee MJ, Balentine D, Kuo MC, Schantz SP (1998) Blood and urine levels of tea catechins after ingestion of different amounts of green tea by human volunteers. Cancer Epidemiol Biomark Prev 7:351-354.

Yang F, Oz HS, Barve S, De Villiers WJ, McClain CJ, Varilek GW (2001) The green tea polyphenol (-)-epigallocatechin-3-gallate blocks nuclear factor- $\kappa \mathrm{B}$ activation by inhibiting I $x$ B kinase activity in the intestinal epithelial cell line IEC-6. Mol Pharmacol 60:528-533. 
